\title{
HEAT-RESISTANT CONCRETE BASED ON ALUMINA CEMENT FROM SUBSTANDARD RAW MATERIAL
}

\author{
R. M. Vorozhbiyan, ${ }^{1}$ G. N. Shabanova,,$^{1,2}$ and A. N. Korogodskaya ${ }^{1}$
}

Translated from Novye Ogneupory, No. 9, pp. 47 - 51, September, 2018.

Original article submitted June 13, 2018.

Results are provided for development of refractory concrete based on modified alumina cement using chemical industry waste. A quantitative ratio for mixed filler fractions, the effect of production factors on concrete strength, the dependence of its strength properties on form of filler, and solidification conditions are established. It is shown that with respect to physicomechanical and engineering properties the concretes developed is no worse than those existing in the market. With respect to all engineering properties this form of refractory product may be recommended as lining for high-temperature units.

Keywords: alumina cement, refractory concrete, water-treatment sludge, catalyst support waste.

\section{INTRODUCTION}

It is possible to prepare assembled structures of any configuration from refractory concrete and this makes it possible to obtain new structural solutions for heating units most expedient from a heat engineering and production point of view [1]. Use of refractory concrete opens up considerable possibilities in industrialization of labor consuming work and makes it possible thereby to reduce construction duration and routine repair of high-temperature units with a significant reduction in cost and an increase in operating life. Use of heat-resistant concrete is aimed at structural solutions for high-temperature industrial furnace elements, difficult to make using individual refractories [3, 4]. In addition, refractory concretes are use in various branches of industry [5-7]. In view of the fact that the main component of refractory concrete is alumina cement it is expedient to us refractory binder materials prepared by resource saving technology.

\section{RESEARCH MATERIALS AND METHODS}

In order to prepare high-strength refractory concrete with the required operating properties the optimum grain size composition was selected for filler taking account of strength, density, and uniformity. The binder used was modified alumina cement of optimum composition prepared on

1 NTU, KhPI, Khar'kov, Ukraine.

2 gala-shabanova@ukr.net the basis of water-treatment sludge and catalyst K-905 D2 support waste in a ratio of 50:50 and having the best strength properties under different hardening conditions and times [Table 1) $[8,9]$.

Grinding and careful mixing raw components was performed in a laboratory porcelain mill to complete passage through a screen No. 0063. The prepared mixture was dried in a laboratory drying cabinet at $100-105^{\circ} \mathrm{C}$ to complete moisture removal after which using the mixture in a hydraulic press under a pressure of $20 \mathrm{MPa}$ specimens were compacted $50 \mathrm{~mm}$ in diameter and $50-70 \mathrm{~mm}$ thick. Specimens were fired in a laboratory cryptolite furnace at $1380^{\circ} \mathrm{C}$ with isothermal exposure at the maximum temperature for $3 \mathrm{~h}$. The rate of temperature increase with $50-70{ }^{\circ} \mathrm{C} / \mathrm{min}$. after firing specimens were subjected to rapid cooling. Clinker of the prepared cement was ground to complete passage through a screen no. $008[10,11]$. Completeness of occur-

TABLE 1. Results of Physicomechanical Tests for Alumina Cement Based on Catalyst Carrier Waste

\begin{tabular}{ccccc}
\hline $\begin{array}{c}\text { Catalyst carrier } \\
\text { waste : water } \\
\text { treatment sludge }\end{array}$ & M/S & \multicolumn{4}{c}{$\begin{array}{c}\text { Ultimate strength in compression, MPa, } \\
\text { after solidification }\end{array}$} \\
\hline $50: 50$ & 0.31 & 58 & 62 & 66 \\
$45: 55$ & 0.29 & 48 & 55 & 60 \\
$40: 60$ & 0.30 & 48 & 50 & 52 \\
$60: 40$ & 0.30 & 50 & 53 & 60 \\
\hline
\end{tabular}




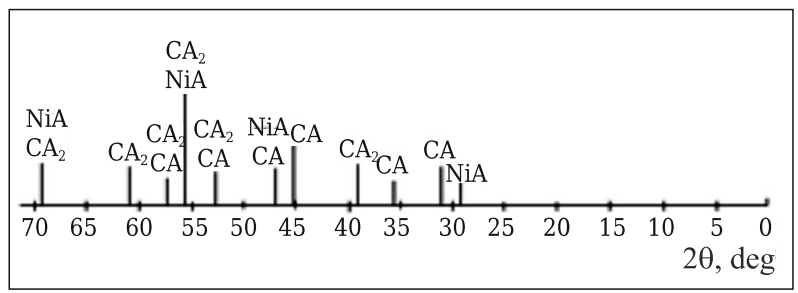

Fig. 1. Line-diffraction pattern of alumina cement clinker prepared from water treatment sludge and catalyst carrier waste K-904 D2: $\mathrm{CA}$ is calcium monoaluminate $\mathrm{CaAl}_{2} \mathrm{O}_{4} ; \mathrm{CA}_{2}$ is calcium dialuminate $\mathrm{CaAl}_{4} \mathrm{O}_{7} ; \mathrm{NiA}$ is nickel spinel $\mathrm{NiAl}_{2} \mathrm{O}_{4}$.

rence of synthesis of the main sinter minerals was monitored by chemical and $\mathrm{x}$-ray analysis methods (Fig. 1). It was established that the main phases are $\mathrm{CaAl}_{2} \mathrm{O}_{4}(0.4049,0.3715$, $0.297,0.2851,0.2534,0.2403 \mathrm{~nm}), \quad \mathrm{CaAl}_{4} \mathrm{O}_{7} \quad(0.3509$, $0.2534,0.2438,0.2403,0.2219,0.2021 \mathrm{~nm})$, and also $\mathrm{NiAl}_{2} \mathrm{O}_{4}(0.467,0.2851,0.2438,0.2021 \mathrm{~nm})[1]$.

\section{EXPERIMENTAL SECTION}

The filler used was high-alumina chamotte produced by PAO Kondrat'ev Refractory Plant and the cement:filler ration equals 1:3.

Concrete cubic specimens with a side of $2 \mathrm{~cm}$ were prepared by vibration compaction $(\mathrm{L} / \mathrm{S}=0.08)$. The optimum ratio of grain sizes for the mixed filler fractions was determined by an equation [1]

$$
d_{n} / d_{n-1}=0.226,
$$

where $d_{n}$ is average grain fine fraction diameter; $d_{n-1}$ is average coarse grain fraction diameter.

The quantitative ratio of mixed fractions of filler was determined by a simplex lattice experimental planning method. In order to describe the dependence of concrete properties on the quantitative ratio of filler fractions an incomplete third order polynomial was used

$$
\begin{aligned}
Y=\beta_{1} x_{1}+\beta_{2} x_{2} & +\beta_{3} x_{3}+\beta_{12} x_{1} x_{2} \\
& +\beta_{13} x_{1} x_{3}+\beta_{23} x_{2} x_{3}+\beta_{123} x_{1} x_{2} x_{3} .
\end{aligned}
$$

The experimental planning matrix and results of mechanical property tests for concretes are provided in Table 2 . From results of experimental data polynomial coefficients were calculated expressing the dependence of strength and porosity on the quantitative and grain size ratio of filler fractions. Regression equations have the form

$$
\begin{gathered}
Y_{\sigma}=30 \cdot x_{1}+41 \cdot x_{2}+53 \cdot x_{3}+14 \cdot x_{1} x_{2} \\
+18 \cdot x_{1} x_{3}+16 \cdot x_{2} x_{3}+225 \cdot x_{1} x_{2} x_{3}, \\
Y_{n}=18.9 \cdot x_{1}+18.0 \cdot x_{2}+17.7 \cdot x_{3}-1.0 \cdot x_{1} x_{2} \\
-1.6 \cdot x_{1} x_{3}-0.2 \cdot x_{2} x_{3}-7.8 \cdot x_{1} x_{2} x_{3} .
\end{gathered}
$$

The adequacy of the equation was checked by means of the Student criterion and additional experimental specimens at control points. The regression equation was calculated by

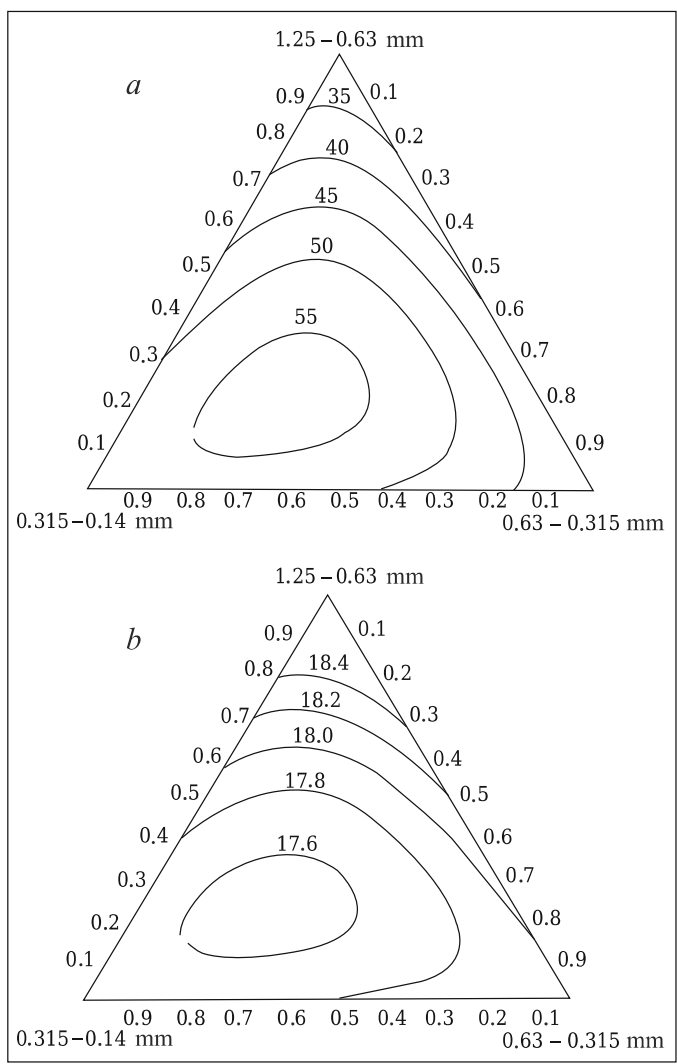

Fig. 2. Composition - ultimate strength in compression, $\mathrm{MPa}(a)$ and composition - open porosity, \% $(b)$, diagrams for concrete based on alumina cement.

a TRIANGLE V.1.0 program with a variation step of $10 \mathrm{wt} \%$. From results of calculations and mathematical treatment of an experiment simplex composition-strength and composition-porosity diagrams were plotted (Fig. 2). It was established that in order to prepare high-strength concrete the density and uniformity of the mixture required contained $10-35 \mathrm{wt} . \%$ fraction $1.25-0.63 \mathrm{~mm}, 15-45 \mathrm{wt} . \%$

TABLE 2. Experimental Planning Matrix

\begin{tabular}{lcccccc}
\hline & \multicolumn{3}{c}{ Filler fraction } & & \multicolumn{2}{c}{ Experimental data } \\
\cline { 2 - 3 } \cline { 5 - 6 } $\begin{array}{c}\text { Polynomial } \\
\text { coefficient }\end{array}$ & & & & & $Y_{\sigma}$ & $Y_{n}$ \\
\cline { 5 - 6 } & $x_{1}$ & $x_{2}$ & $x_{3}$ & $\begin{array}{c}\text { ultimate strength } \\
\text { in compression, } \\
\text { MPa }\end{array}$ & $\begin{array}{c}\text { open } \\
\text { porosity, } \%\end{array}$ \\
\hline$\eta_{1}$ & 1 & 0 & 0 & & 30.0 & 18.9 \\
$\eta_{2}$ & 0 & 1 & 0 & & 41.0 & 18.0 \\
$\eta_{3}$ & 0 & 0 & 1 & & 53.0 & 17.7 \\
$\eta_{12}$ & 0.5 & 0.5 & 0 & & 39.0 & 18.2 \\
$\eta_{13}$ & 0.5 & 0 & 0.5 & & 46.0 & 17.9 \\
$\eta_{23}$ & 0 & 0.5 & 0.5 & & 51.0 & 17.8 \\
$\eta_{123}$ & 0.33 & 0.33 & 0.33 & 55.0 & 17.6 \\
Control & 0.5 & 0.3 & 0.2 & 49.0 & 17.8 \\
point & & & & & \\
\hline
\end{tabular}




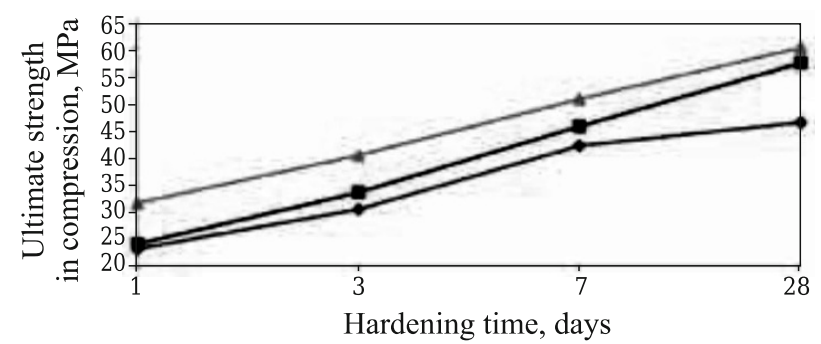

Fig. 3. Effect of production factors on concrete strength: $\bullet$ ) manual tamping; $\boldsymbol{\square}$ ) vibration compaction; $\boldsymbol{\Delta}$ ) pressing.

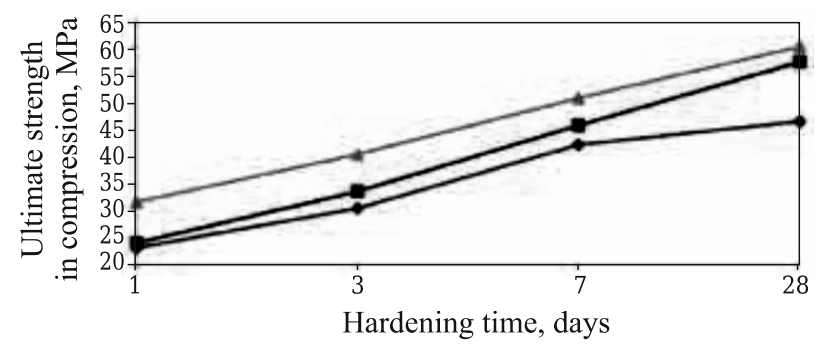

Fig. 4. Dependence of concrete strength on form of filler with hardening in moist air $(a)$ and atmospheric conditions $(b): \triangle$ ) highalumina chamotte; $\boldsymbol{\square})$ chamotte; $\diamond$ ) electromelted corundum; $\times$ ) deposit chips.

$0.63-0.315 \mathrm{~mm}$, and $30-65$ wt. $\% 0.315-0.50 \mathrm{~mm}$. Further study of concretes was performed taking account of the optimum filler grain size composition.

In order to study the effect of different molding methods on the mechanical strength of concretes prepared on the basis of modified alumina cement cubic specimens were prepared with a side of $5 \mathrm{~cm}$. Results of studies showed (Fig. 3) that the most suitable is the vibration compaction method, most appropriate for preparing large objects of complex configuration. Use of a compaction method makes it possible to produce individual refractories.

In order to determine the optimum ratio in concrete of cement:filler an experiment was conducted on concrete cubic specimens with a side of $4 \mathrm{~cm}$ prepared by vibration compaction with $L / S=0.08$. Results are given in Table 3 for physicomechanical tests of concrete in relation to ratio within it of cement and filler. It is seen that with an increase in cement content the strength of solidified concrete in-

TABLE 3. Dependence of Concrete Strength and Porosity on Cement:Filler Ratio

\begin{tabular}{ccccc}
\hline \multirow{2}{*}{$\begin{array}{c}\text { Cement:filler } \\
\text { ratio }\end{array}$} & \multicolumn{3}{c}{$\begin{array}{c}\text { Ultimate strength in compression, MPa, after } \\
\text { hardening }\end{array}$} & $\begin{array}{c}\text { Open poros- } \\
\text { ity, } \%\end{array}$ \\
\cline { 2 - 4 } & 3 days & 7 days & 28 days & \\
\hline $1: 9$ & 25.3 & 27.3 & 40.2 & 18.0 \\
$1: 4$ & 28.8 & 37.4 & 50.8 & 17.8 \\
$1: 3$ & 33.4 & 48.6 & 57.9 & 17.4 \\
$1: 2.3$ & 35.1 & 49.2 & 58.2 & 17.2 \\
\hline
\end{tabular}

creases, but conversely porosity decreases. This indicates that the cement added not only participates actively in forming concrete strength, but also leads to a reduction in porosity. The optimum ratio providing the required strength and economy for cement is cement:filler $=1: 3$.

With subsequent use of the concrete developed in various branches comparative evaluation is required for the selected fillers. The fillers used were electromelted corundum and chamotte produced by PAO A. S. Berezhnyi Ukraine Sci.-Res. Institute of Refractories, high-alumina chamotte produced by PAO Kondrat'ev Refractory Plant, and chips of deposits from furnaces for producing alumina cement. Concrete specimens with a different filler prepared by vibration compaction were selected for mechanical strength under different hardening conditions. The effect of form of filler and hardening conditions on concrete mechanical strength is shown in Fig. 4. Heat-resistant concretes based on filler of high-alumina chamotte had the highest strength. Therefore, on the basis of alumina cement obtained from water-treatment sludge and catalyst support waste of the North Donetsk Azot firm it is possible to obtain concrete with the best strength properties and reduced open porosity, which makes it possible to employ them as a monolithic lining for thermally stressed sections of high-temperature units.

Concrete thermomechanical properties were also studied. Refractoriness of concrete based on electromelted corundum, measured by collapse of a pyrometric cone, comprised $1750^{\circ} \mathrm{C}$, for chamotte $1500^{\circ} \mathrm{C}$, for high-alumina chamotte, $1550^{\circ} \mathrm{C}$, and a for deposit chips of $1650^{\circ} \mathrm{C}$. Therefore, the concrete obtained may be used in heating units at service temperatures up to $1500^{\circ} \mathrm{C}$, depending on the filler selected. Concrete thermal shock resistance with different fillers (specimen cooling in air) comprises more than 20 cycles, retaining more than $80 \%$ of the initial strength.

Specimens of cylindrical shape were prepared in order to determine the temperature for the start of concrete softening. Specimens C were prepared based on a corundum filler, and specimen $\mathrm{Ch}$ based on chamotte; the binder used was experimental alumina cement (Fig. 5). Specimen dimensions are given in Table 4 and correspond to standard specifications.

Specimens $\mathrm{C}$ and $\mathrm{Ch}$ were tested in a certified test unit according to GOST 4070-2000)ISO 1893-89) "Refractory objects. Method for determining deformation temperature under load." Specimen deformation was measured by a differential method using differential measuring equipment prepared from single crystal corundum. During testing for each of the specimens the load applied answered a pressure of $0.02 \pm 0.01 \mathrm{~N} / \mathrm{mm}^{2}$. The rate of specimen temperature increase up to $300^{\circ} \mathrm{C}$ was not greater than $10^{\circ} \mathrm{C} / \mathrm{min}$, and above $300^{\circ} \mathrm{C}$ it was $4.5^{\circ} \mathrm{C} / \mathrm{min}$. Test results: for specimen $\mathrm{C}$ $t_{0.6}=(1290 \pm 10)^{\circ} \mathrm{C}$, for specimen $\mathrm{Ch} t_{0.6}=(1230 \pm 10)^{\circ} \mathrm{C}$. measurement uncertainty for the temperature fort eh start of softening was calculated in accordance with RMG 43-2001 "State system providing measurement unification. Use of guidance for expressing measurement uncertainty."

An important operating property of alumina concrete is the degree of softening on heating. In order to study concrete 


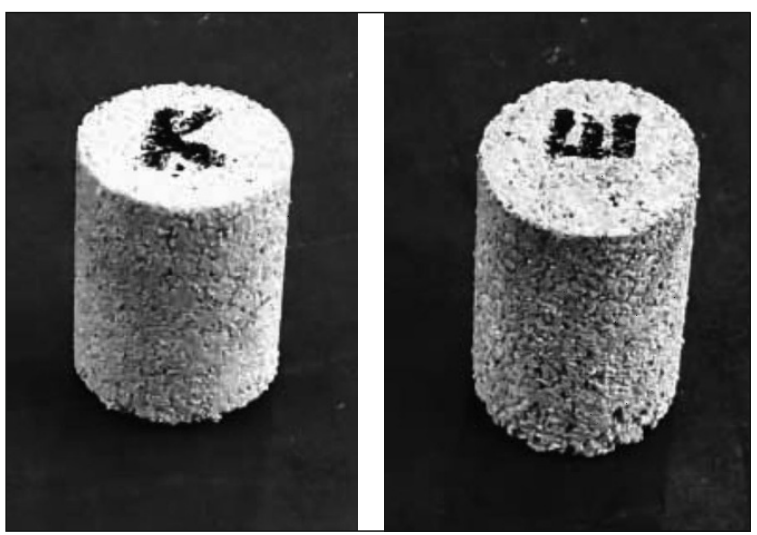

Fig. 5. Test specimens (without visible damage).

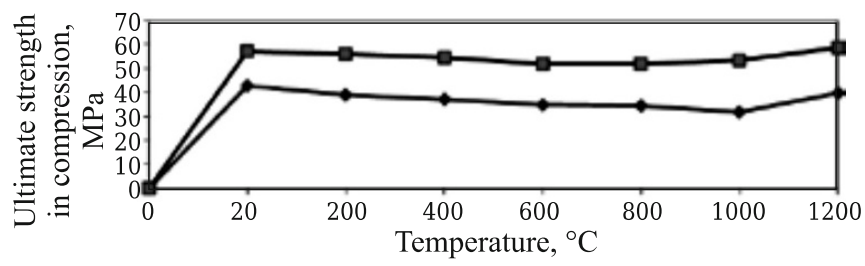

Fig. 6. Dependence of concrete strength on temperature and form of filler : - ) high-alumina chamotte $\diamond$ )electromelted corundum; $\times$ ) deposit chips.

TABLE 4. Specimen Technical parameters

\begin{tabular}{ccc}
\hline \multirow{2}{*}{$\begin{array}{c}\text { Specimen identification } \\
\text { designation }\end{array}$} & \multicolumn{2}{c}{ Specimen size, mm } \\
\cline { 2 - 3 } C & diameter & thickness \\
\hline Ch & 36.0 & 50.9 \\
& 35.8 & 52.9 \\
\hline
\end{tabular}

mechanical strength with action of elevated temperature cubic specimens were prepared with a side of $5 \mathrm{~cm}$ that were tested after 28 days of hardening. Isothermal exposure for $2 \mathrm{~h}$ at a prescribed temperature with rapid cooling in air. The filler used was chamotte and high-alumina chamotte, i.e., materials exhibiting the closest matrix affinity for cement an filler. Test results for concretes with action elevated temperature are shown in Fig. 6. Concrete with different fillers on heating behaves approximately the same. Concrete based on filler of high-alumina chamotte loses strength up to $9.6 \%$ of the initial value, but concrete based on chamotte loses up to $20 \%$ of the initial strength. The greatest increase in the degree of loss of concrete strength is observed in the range $400-800^{\circ} \mathrm{C}$ that is explained by removal of crystallization water from calcium hydroaluminate and aluminum hydroxide, and also recrystallization of hexagonal calcium aluminate, which facilitates occurrence of internal stresses and insignificant concrete weakening. Above $800^{\circ} \mathrm{C}$ weakening slows down, and above $1000^{\circ} \mathrm{C}$ sintering of the binder and its reaction with filler commence, which facilitates a significant increase in strength with formation of a dense ceramic structure. Loss of strength for concrete based on normal alumina cement with traditional fillers in the test temperature range exceeds $28 \%$ and may reach $40 \%$, which is higher by a factor of $2-4$ than for the concrete developed.

\section{CONCLUSION}

It has been established that concretes prepared on the basis of modified alumina cement have a number of advantages compared with existing analogs and are characterized by equal setting time, high initial strength, and absence of a significant loss of strength after 28 days of hardening. These concretes may be used for preparing both a large lining of complex configuration, and also individual refractories with an operating temperature above $1500^{\circ} \mathrm{C}$. It has been established that with respect to high-temperature operating properties the concretes developed are no worse than the best overseas analogs and are promising refractory materials for use in various industries.

\section{REFERENCES}

1. R. M. Vorozhbiyan, G. N. Shabanova, and S. M. Korogodskaya, "Alumina cements based on $\mathrm{CaO}-\mathrm{NiO}-\mathrm{Al}_{2} \mathrm{O}_{3}$," Novye Ogneupory Tekhn. Keram., No. 11/12, 11 - 14 (2012).

2. R. Vorozhbiian, H. Shabanova, T. Ryshchenko, "Alumina cement on chemical industry wastes," 19 International Baustofftagung, 16-18 September, 2015, Tagungsbericht, Band 2, Weimar, Bundesrepublik, Deutschland (2015).

3. M. T. Mel'nik and N. Sh. Shapovalova, Refractory Cements [in Russian], Vysshaya Shkola, Kiev (1984).

4. T. V. Kuznetsova and I. Talaber, Alumina Cement [in Russian] Stroiizdat, Moscow (1988).

5. O. O. Pashchenko, V. P. Serbin, and O. O. Starchevs'ka, Viscous Materials [in Ukrainian], Vishcha Shkola, Kiev (1995).

6. A. A. Pashchenko, cement Theory [in Russian], Budevel'nik, Kiev (1991).

7. M. T. Mel'nik and N. N. Shapalova, "Refractory concrete based on alumina cement with addition of active alumina," Ogneupory, No. 10, 56 - 57 (1974).

8. R. M. Vorozhbiyan, G. N. Shabanova, A. N. Korogodskaya, et al., "Basis of possible use of nickel catalyst waste in the production of alumina cement," Zbirnik, Nauk. Prats' VAT UkrNDIVognetriviv im A. S. Berezhnogo, No. 112, 223 - 229 (2012).

9. R. M. Vorozhbiyan, G. N. Shabanova, and A. N. Korogodskaya, "Questions of using water cleaning waste in alumina cement manufacture," Visnik NTU KhGP, No. 27, 164 - 173 (2011).

10. R. M. Vorozhbiyan, G. M. Shabanova, A. M. Korohods'ka, et al., Equal characteristics of aluminum oxide cements with the use of approaches employed in chemical plants, Zb. Naukovykh Prats' PAT UkrNDIVognetriviv im. A. S. Berezhnogo, No. 113, 86 - 93 (2013).

11. R. M. Vorozhbiyan, G. M. Shabanova, A. M. Korohods'ka, and T. D. Ryshchenko, High-efficiency specialized viscous materials based on alkali-earth oxides, Zb. Nauk. Prats' Ukrains'k. Derzh. Akad. Zaliz. Transportu, No. 138, 27 - 32 (2011). 